\title{
Appendectomy for Appendicitis Has Worse Hospital Outcomes in Inflammatory Bowel Disease Patients
}

\author{
Ravi Babu Pavurala1, Andrea Johnson'2, Alice Hinton ${ }^{3}$, \\ Somashekar G. Krishna ${ }^{2}$, Anita Afzali ${ }^{2}$, Cheng Zhang** \\ ${ }^{1}$ Department of Medicine, College of Medicine, The Ohio State University, Columbus, OH, USA \\ ${ }^{2}$ Division of Gastroenterology, Hepatology, \& Nutrition, College of Medicine, The Ohio State University, Columbus, OH, USA \\ ${ }^{3}$ Division of Biostatistics, College of Public Health, The Ohio State University, Columbus, OH, USA \\ ${ }^{4}$ Department of Gastroenterology, MercyCrest Gastroenterology, Springfield, OH, USA \\ Email: *czhang@mercy.com
}

How to cite this paper: Pavurala, R.B., Johnson, A., Hinton, A., Krishna, S.G., Afzali, A. and Zhang, C. (2018) Appendectomy for Appendicitis Has Worse Hospital Outcomes in Inflammatory Bowel Disease Patients. Journal of Biosciences and Medicines, 6, 23-35.

https://doi.org/10.4236/jbm.2018.65004

Received: January 19, 2018

Accepted: May 18, 2018

Published: May 21, 2018

\begin{abstract}
Background and Aims: Appendectomy is the choice of surgery for appendicitis but little is known about its outcomes in patients with Inflammatory Bowel Disease (IBD). We sought to compare hospital outcomes of appendectomy for appendicitis between patients with and without IBD. Methods: This is a cross-sectional study utilizing the Nationwide Inpatient Sample between 2009 and 2013. Patients with appendicitis undergoing appendectomy were identified using appropriate International Classification of Diseases codes. Primary outcomes of interest included length of stay (LOS), hospital costs, and post-surgical complications. Univariate and multivariate analyses were used to compare these outcomes between patients with and without IBD. Results: A total of 849,312 patients with appendicitis undergoing appendectomy were included in this study, of which 4261 patients had IBD. IBD patients had longer LOS and increased hospital costs. Crohn's disease (CD) patients were more likely to develop post-operative pulmonary embolism (adjusted odds ratio (aOR) 7.06, 95\% Confidence Interval (CI) $(2.19,22.79)$ ) and anemia (aOR $2.23,95 \%$ CI $(1.21,4.10))$, whereas ulcerative colitis patients were more likely to develop post-operative deep vein thrombosis (aOR 9.79, 95\% CI (2.41, 39.75)). CD patients were more likely to have perforated appendicitis (aOR $1.37,95 \%$ CI $(1.67,1.11))$ and open appendectomy (aOR 1.56, 95\% CI $(1.96$, 1.27)). Conclusions: Appendectomy for appendicitis in IBD patients is associated with adverse hospital outcomes. Focused attempts are needed to decrease the risk of DVT and PE in these patients. Treating patient's pre-surgical anemia and proactive venous thromboembolism prophylaxis in IBD patients
\end{abstract}


undergoing appendectomy for appendicitis might improve hospital outcomes.

\section{Keywords}

Ulcerative Colitis, Crohn's Disease, Inflammatory Bowel Disease, Appendicitis, Appendectomy, Outcomes

\section{Introduction}

Inflammatory Bowel Disease (IBD) consists of ulcerative colitis (UC) and Crohn's disease (CD), which are characterized by chronic inflammation with relapsing and remitting course involving the colonic mucosa and entire gastrointestinal tract, respectively [1] [2]. Both conditions result in decreased quality of life and increased morbidity [3] [4] [5]. Hospitalization due to IBD burdens the healthcare resource utilization system; the mean annual hospitalization cost for a CD patient was $\$ 2595$ and $\$ 1895$ for a UC patient between 2003 and 2004 [6].

Acute appendicitis is a common diagnosis with a lifetime incidence risk of about $8 \%$ among the general population [7]. The treatment of choice is laparoscopic appendectomy owing to less wound complications and faster recovery times [8]. Though it is one of the common emergent abdominal surgeries among hospitalized patients, not much is known about the hospital outcomes in IBD patients. Association of appendectomy with IBD has been studied previously, but there is paucity of research addressing the hospital outcomes of IBD patients undergoing appendectomy.

Thus we sought to compare hospital outcomes including in-hospital mortality, post-surgical complications, length of hospital stay and hospital costs between patients with and without IBD who underwent appendectomy for appendicitis.

\section{Methods}

\subsection{Data Sources}

All data were extracted from the Nationwide Inpatient Sample (NIS) between 2009 and 2013. NIS is the largest all-payer inpatient database in the United States. The database represents approximately a $20 \%$ sample of nonfederal, acute-care hospitals in the United States. The sampling frame includes community and general hospitals and academic medical centers comprising approximately $90 \%$ of all-hospital discharges in the United States. Each data entry includes a unique identifier, demographic variables (including age, gender and race/ethnicity), type of admission, source of admission, principal and secondary diagnoses, primary insurance payer, total hospital charges, and length of stay (LOS). Missing demographic information was summrized in Supplementary

Table S1. Healthcare resource utilization included LOS and hospital costs. The comorbidity burden was stratified based on Elixhauser score $<3$ and $\geq 3$ [9]. 
The "Data and Specimen Policy" and "Human Subjects Research Policy" at The Ohio State University does not require Institutional Review Board approval for population-based public data set [10].

\subsection{Study Population and Definition of Variables}

Our study consisted of all adult patients ( $\geq 18$ years old) who had a principal discharge diagnosis of appendicitis and underwent appendectomy, identified by appropriate International Classification of Diseases, Ninth Revision, and Clinical Modification codes (ICD-9-CM) (Appendix 1). The patients were considered to have IBD if the secondary discharge diagnosis was either UC or CD. These criteria have been previously used and validated at a tertiary care academic center [9] [11]. Elective admissions and patients with discharge diagnoses of both UC and CD were excluded.

\subsection{Outcomes}

Our outcomes of interest were In-hospital Mortality, LOS, total hospital cost and incidence of post-surgical complications.

\subsection{Statistics}

Statistical analysis was performed using SAS 9.4 (SAS Institute, Cary, NC), employing appropriate survey estimation commands and strata weights. Continuous variables were summarized with means and confidence intervals. Categorical variables were summarized with frequencies and percentages. Differences between patients with and without IBD undergoing appendectomy were analyzed using $\mathrm{X}^{2}$ tests or Student's t-tests, as appropriate. Multivariate logistic regression was used to calculate adjusted odds ratios and corresponding $95 \%$ confidence intervals for in-hospital mortality, incidence of post-surgical complications, and all other bivariate outcomes. Multivariate linear regression was used to analyze LOS and hospital cost. Each multivariate model was adjusted for patient demographics and hospital characteristics, sample size permitting. The models for LOS and hospital costs were additionally adjusted for type of appendicitis, surgery type and significant post-operative complications. The mortality and post-operative complications models were additionally adjusted for appendicitis type and surgery type.

\section{Results}

\subsection{Demographic Characteristics of Patients and Hospitals}

A total of 849,312 patients were included during the study period, of which there were 1845 patients with UC $(0.22 \%), 2416$ patients with CD $(0.28 \%)$, and 845,051 patients with no IBD (99.50\%) after 381,592 patients were excluded. Univariate analysis (Table 1 and Supplementary Table S2) demonstrated that patients with UC were more likely to be olde0r and to have more comorbidities, including anemia, chronic blood loss, congestive heart failure, depression, 
Table 1. Univariate analysis of non-inflammatory bowel disease (IBD), Crohn's disease (CD), and ulcerative colitis (UC) patient and hospital characteristics.

\begin{tabular}{|c|c|c|c|c|c|c|c|c|}
\hline \multirow[b]{2}{*}{ Age (mean, SE) } & \multicolumn{2}{|c|}{$\begin{array}{c}\text { No IBD } \\
(\mathrm{n}=\mathbf{8 4 5 , 0 5 1 )} \\
\end{array}$} & \multicolumn{2}{|c|}{$\begin{array}{c}C D \\
(\mathrm{n}=2416)\end{array}$} & \multirow{2}{*}{$\begin{array}{c}\text { p-value } \\
0.967\end{array}$} & \multicolumn{2}{|c|}{$\begin{array}{c}\text { UC } \\
(\mathrm{n}=1845)\end{array}$} & \multirow{2}{*}{$\begin{array}{c}\text { p-value } \\
<0.001\end{array}$} \\
\hline & 41.44 & 0.08 & 41.46 & 0.72 & & 44.99 & 0.81 & \\
\hline Sex & & & & & 0.380 & & & 0.672 \\
\hline Male & 446,401 & $53.31 \%$ & 1235 & $51.30 \%$ & & 1000 & $54.43 \%$ & \\
\hline Female & 390,956 & $46.69 \%$ & 1173 & $48.70 \%$ & & 837 & $45.57 \%$ & \\
\hline Race & & & & & $<0.001$ & & & $<0.001$ \\
\hline White & 493,815 & $64.38 \%$ & 1686 & $77.79 \%$ & & 1,424 & $83.39 \%$ & \\
\hline Black & 57,904 & $7.55 \%$ & 185 & $8.52 \%$ & & 113 & $6.62 \%$ & \\
\hline Hispanic & 150,255 & $19.59 \%$ & 184 & $8.47 \%$ & & 114 & $6.67 \%$ & \\
\hline Other & 65,104 & $8.49 \%$ & 113 & $5.22 \%$ & & 57 & $3.33 \%$ & \\
\hline Insurance & & & & & $<0.001$ & & & $<0.001$ \\
\hline Medicare & 102,771 & $12.20 \%$ & 337 & $14.01 \%$ & & 284 & $15.40 \%$ & \\
\hline Medicaid & 103,107 & $12.24 \%$ & 232 & $9.63 \%$ & & 140 & $7.59 \%$ & \\
\hline Private & 459,099 & $54.49 \%$ & 1545 & $64.19 \%$ & & 1,259 & $68.24 \%$ & \\
\hline Other & 177,632 & $21.08 \%$ & 293 & $12.17 \%$ & & 162 & $8.77 \%$ & \\
\hline Income Quartile & & & & & 0.491 & & & $<0.001$ \\
\hline 1 & 190,784 & $23.12 \%$ & 511 & $21.52 \%$ & & 278 & $15.58 \%$ & \\
\hline 2 & 196,955 & $23.87 \%$ & 549 & $23.14 \%$ & & 393 & $21.97 \%$ & \\
\hline 3 & 217,250 & $26.33 \%$ & 608 & $25.60 \%$ & & 486 & $27.18 \%$ & \\
\hline 4 & 220,093 & $26.68 \%$ & 706 & $29.73 \%$ & & 630 & $35.27 \%$ & \\
\hline Elixhauser Comorbidity & & & & & $<0.001$ & & & $<0.001$ \\
\hline$<3$ & 765,867 & $90.63 \%$ & 2,082 & $86.15 \%$ & & 1,529 & $82.88 \%$ & \\
\hline$\geq 3$ & 79,184 & $9.37 \%$ & 335 & $13.85 \%$ & & 316 & $17.12 \%$ & \\
\hline Hospital Bed Size & & & & & 0.692 & & & 0.362 \\
\hline Small & 116,963 & $13.92 \%$ & 361 & $14.96 \%$ & & 239 & $13.00 \%$ & \\
\hline Medium & 222,620 & $26.50 \%$ & 658 & $27.29 \%$ & & 437 & $23.82 \%$ & \\
\hline Large & 500,389 & $59.57 \%$ & 1,393 & $57.76 \%$ & & 1,160 & $63.18 \%$ & \\
\hline Hospital Type & & & & & 0.360 & & & 0.323 \\
\hline Rural & 94,489 & $11.25 \%$ & 308 & $12.78 \%$ & & 179 & $9.74 \%$ & \\
\hline Urban Non-Teaching & 402,265 & $47.89 \%$ & 1,187 & $49.22 \%$ & & 841 & $45.81 \%$ & \\
\hline Urban Teaching & 343,218 & $40.86 \%$ & 917 & $38.00 \%$ & & 816 & $44.45 \%$ & \\
\hline Hospital Region & & & & & 0.019 & & & 0.007 \\
\hline Northeast & 186,259 & $22.04 \%$ & 544 & $22.52 \%$ & & 514 & $27.88 \%$ & \\
\hline Midwest & 145,426 & $17.21 \%$ & 534 & $22.10 \%$ & & 369 & $19.99 \%$ & \\
\hline South & 287,006 & $33.96 \%$ & 799 & $33.07 \%$ & & 539 & $29.23 \%$ & \\
\hline West & 226,361 & $26.79 \%$ & 539 & $22.30 \%$ & & 423 & $22.90 \%$ & \\
\hline Appendicitis Type & & & & & 0.001 & & & 0.422 \\
\hline Perforated & 231,732 & $27.42 \%$ & 821 & $33.97 \%$ & & 472 & $25.59 \%$ & \\
\hline Non-Perforated & 613,320 & $72.58 \%$ & 1596 & $66.03 \%$ & & 1,373 & $74.41 \%$ & \\
\hline Surgery Type ${ }^{1}$ & & & & & $<0.001$ & & & 0.486 \\
\hline Open & 183,078 & $21.66 \%$ & 744 & $30.80 \%$ & & 427 & $23.15 \%$ & \\
\hline Laparoscopic & 661,974 & $78.34 \%$ & 1672 & $69.20 \%$ & & 1,418 & $76.85 \%$ & \\
\hline
\end{tabular}

${ }^{1}$ Patients with codes for both open and laparoscopic procedures were classified as open. 
hypertension, liver disease, fluid and electrolyte disorders, valvular disease and weight loss when compared with patients without IBD. Patients with CD were more likely to have anemia, rheumatoid arthritis or collagen vascular disease, coagulopathy, fluid and electrolyte disorders, psychoses, and weight loss compared to patients without IBD.

Multivariate analysis adjusting for age, gender, race, insurance, income, Elixhauser score, and hospital size, type and region revealed that, UC patients were more likely to have non-perforated appendicitis (aOR 1.36, 95\% CI $(1.04,1.79)$ ) when compared with non-IBD patients (Table 2). CD patients were more likely to have perforated appendicitis (aOR 1.37, 95\% CI $(1.67,1.11)$ ) and require open appendectomies (aOR 1.56, 95\% CI $(1.96,1.27)$ ) (Table 3 ).

\subsection{Outcomes}

\subsubsection{Mortality}

In-hospital mortality was not different between $\mathrm{CD}$ and non-IBD patients after appendectomy and we were unable to compare the mortality between UC and non-IBD patients, as there were no deaths among the UC patients.

\subsubsection{Hospital Resource Utilization (Length of Stay and Hospital Cost)}

After adjusting for patient and hospital characteristics, appendicitis type (non-perforated versus perforated), surgery type (laparotomy versus open) and significant post-surgical complications, both UC and CD patients after appendectomy had longer LOS (adjusted coefficient, 0.45 days, 95\% CI $(0.11,0.79)$; adjusted coefficient, 0.91 days, $95 \% \mathrm{CI}(0.69,1.14)$, respectively) when compared

Table 2. Univariate and multivariate analyses of length of stay (LOS), hospital costs, post-operative deep vein thrombosis, type of appendicitis and type of surgery between patients with UC and no IBD.

\begin{tabular}{|c|c|c|c|c|c|c|}
\hline \multirow[b]{3}{*}{ Length of Stay ${ }^{1}$ (days) } & \multicolumn{3}{|c|}{ Univariate } & \multicolumn{3}{|c|}{ Multivariate } \\
\hline & \multicolumn{2}{|c|}{$\begin{array}{c}\text { Odds ratio } \\
\text { (OR)/Coefficient } \\
(95 \% \mathrm{CI})\end{array}$} & \multirow{2}{*}{$\begin{array}{c}\text { p-value } \\
<0.001\end{array}$} & \multicolumn{2}{|c|}{$\begin{array}{c}\text { Adjusted OR } \\
\text { (aOR)/Coefficient } \\
(95 \% \mathrm{CI})\end{array}$} & \multirow{2}{*}{$\begin{array}{r}\text { p-value } \\
0.010\end{array}$} \\
\hline & 0.72 & $(0.31,1.12)$ & & 0.45 & $(0.11,0.79)$ & \\
\hline $\operatorname{Cost}^{1}(\$)$ & 1473 & $(364,2583)$ & 0.009 & 902 & $(10,1,794)$ & 0.047 \\
\hline Deep Vein Thrombosis ${ }^{2}$ & 10.75 & $(2.63,43.89)$ & $<0.001$ & 9.79 & $(2.41,39.75)$ & 0.001 \\
\hline Appendicitis Type ${ }^{3}$ & & & 0.432 & & & 0.026 \\
\hline Perforated & & Reference & & & Reference & \\
\hline Non-Perforated & 1.10 & $(0.87,1.38)$ & & 1.36 & $(1.04,1.79)$ & \\
\hline Surgery Type ${ }^{3,4}$ & & & 0.475 & & & 0.747 \\
\hline Open & & Reference & & & Reference & \\
\hline Laparoscopic & 0.92 & $(0.72,1.17)$ & & 0.96 & $(0.73,1.25)$ & \\
\hline
\end{tabular}

${ }^{1}$ Adjusted for age, gender, race, insurance, income, Elixhauser score, hospital size, type, and region, appendicitis type, surgery type and deep vein thrombosis. ${ }^{2}$ Adjusted for age, race, insurance, income, and Elixhauser score. ${ }^{3}$ Adjusted for age, gender, race, insurance, income, Elixhauser score, hospital size, type, and region. ${ }^{4}$ Patients with codes for both open and laparoscopic procedures were classified as open. 
Table 3. Univariate and multivariate analyses of mortality, LOS, hospital costs, post-operative pulmonary embolism and anemia, type of appendicitis and type of surgery between patients with $\mathrm{CD}$ and no IBD.

\begin{tabular}{|c|c|c|c|c|c|c|}
\hline \multirow[b]{3}{*}{ Mortality $^{1}$} & \multicolumn{3}{|c|}{ Univariate } & \multicolumn{3}{|c|}{ Multivariate } \\
\hline & \multicolumn{2}{|c|}{$\begin{array}{c}\text { Odds ratio } \\
\text { (OR)/Coefficient } \\
\text { (95\% CI) }\end{array}$} & \multirow{2}{*}{$\begin{array}{c}\text { p-value } \\
0.441\end{array}$} & \multicolumn{2}{|c|}{$\begin{array}{c}\text { Adjusted OR } \\
\text { (aOR)/Coefficient } \\
(95 \% \mathrm{CI})\end{array}$} & \multirow{2}{*}{$\begin{array}{r}\text { p-value } \\
0.441\end{array}$} \\
\hline & 2.16 & $(0.30,15.35)$ & & 2.23 & $(0.29,17.06)$ & \\
\hline Length of Stay $^{2}$ (days) & 1.30 & $(1.00,1.60)$ & $<0.001$ & 0.91 & $(0.69,1.14)$ & $<0.001$ \\
\hline $\operatorname{Cost}^{2}(\$)$ & 2,575 & $(1818,3332)$ & $<0.001$ & 1952 & $(1343,2562)$ & $<0.001$ \\
\hline Pulmonary Embolism ${ }^{3}$ & 8.11 & $(2.55,25.79)$ & $<0.001$ & 7.06 & $(2.19,22.79)$ & 0.001 \\
\hline Postoperative Anemia $^{2}$ & 3.02 & $(1.84,4.95)$ & $<0.001$ & 2.23 & $(1.21,4.10)$ & 0.010 \\
\hline Appendicitis Type ${ }^{4}$ & & & 0.001 & & & 0.003 \\
\hline Perforated & 1.37 & $(1.64,1.14)$ & & 1.37 & $(1.67,1.11)$ & \\
\hline Non-Perforated & & Reference & & & Reference & \\
\hline Surgery Type $e^{4,5}$ & & & $<0.001$ & & & $<0.001$ \\
\hline Open & 1.61 & $(1.96,1.32)$ & & 1.56 & $(1.96,1.27)$ & \\
\hline Laparoscopic & & Reference & & & Reference & \\
\hline
\end{tabular}

${ }^{1}$ Adjusted for age, gender, race, insurance, Elixhauser score, hospital type, and region, appendicitis type, and surgery type. ${ }^{2}$ Adjusted for age, gender, race, insurance, income, Elixhauser score, hospital size, type, and region, appendicitis type, surgery type, GI complications, hemorrhage, hematoma, seroma, pulmonary embolism and post-operative anemia. ${ }^{3}$ Adjusted for age, gender, race, insurance, Elixhauser score, hospital region, appendicitis type, and surgery type. ${ }^{4}$ Adjusted for, age, gender, race, insurance, income, Elixhauser score, hospital size, type, and region. ${ }^{5}$ Patients with codes for both open and laparoscopic procedures were classified as open.

with non-IBD patients. Similarly, UC and CD patients had higher hospital costs (adjusted coefficient, \$902, 95\% CI (10, 1794); adjusted coefficient, \$1952, 95\% CI $(1343,2562)$, respectively) when compared with non-IBD patients (Table 2 and Table 3).

\subsubsection{Post-Surgical Deep Vein Thrombosis, Pulmonary Embolism, and Post-Operative Anemia}

After adjusting for patient and hospital characteristics, appendicitis type, and surgery type, $\mathrm{CD}$ patients after appendectomy were more likely to develop pulmonary embolism (PE) (aOR, 7.06, 95\% CI $(2.19,22.79)$ ) and post-operative anemia (aOR, 2.23 , 95\% CI $(1.21,4.10))$ compared to non-IBD patients, whereas UC patients were more likely to develop deep vein thrombosis (DVT) only (aOR, 9.79, 95\% CI $(2.41,39.75)$ ) (Table 2 and Table 3 ).

\section{Discussion}

In this study of the nationwide inpatient database, patients with IBD undergoing appendectomy for appendicitis, although not incurring attributable mortality, was associated with increasing healthcare resource utilization with longer duration of hospitalization, and higher hospital costs. Further, IBD patients also in- 
curred increased risk of post-surgical complications, specifically, DVT in UC patients and $\mathrm{PE}$ and post-operative anemia in patients with $\mathrm{CD}$. Furthermore, patients with $\mathrm{CD}$ were more likely to have perforated appendicitis and open appendectomy compared to patients with no IBD. To our knowledge, this is the first population-based study evaluating hospital outcomes of IBD patients admitted with appendicitis.

While adult patients with non-perforated appendicitis can be safely discharged on the same day after laparoscopic appendectomy without high rates of complications [12], IBD patients in general have higher complexity, increased hospital costs and health resource utilization [13]. The study findings are similar to published data on IBD patients undergoing elective colectomy for colorectal cancer or diverticular disease where they contribute to higher healthcare resource utilization including prolonged hospitalization and higher hospital costs when compared with non-IBD patients [14]. Despite controlling for type of appendicitis and appendectomy, patients with $\mathrm{UC}$ and $\mathrm{CD}$ were associated with longer LOS and higher hospital costs. Compared to patients with UC, those with $\mathrm{CD}$ were more likely to have perforated appendicitis, which may be partially attributed to transmural inflammation associated with $\mathrm{CD}$. Consequently, CD patients required more open appendectomies.

IBD patients undergoing appendectomy for appendicitis had increased risk of DVT or PE, which is in agreement with previous studies [15] [16]. Although chronic inflammation may play a role, DVT or PE could be an extra-intestinal manifestation of IBD as these are not associated with other inflammatory conditions like rheumatoid arthritis and celiac disease [17]. IBD patients have 2 - 3 fold-increased risk of venous thromboembolism [16] [18], particularly after surgery (19). Hence, pharmacologic DVT prophylaxis is recommended in all hospitalized patients with IBD unless contraindicated [18].

Patients with CD, but not UC, were more likely to have post-operative anemia compared to patients without IBD. Anemia is more prevalent in IBD patients due to iron deficiency, anemia of chronic disease, or vitamin B12 deficiency [19] with CD patients having higher incidence than UC patients [20]. In addition, perioperative blood transfusion has been shown to be associated with post-operative infection and worse hospital outcomes in CD [21]. Therefore, pre-operative optimization of anemia, for instance intravenous iron therapy, may improve outcomes of CD patients undergoing surgery [22].

We note that this study has several limitations. Accuracy of ICD-9-CM coding could not be verified by chart review, owing to privacy safeguards. However, the Agency for Healthcare Research and Quality has reviewed the NIS database and found good reliability [23]. In addition, any errors in administrative data should be distributed non-differentially across all groups [24]. Furthermore, administrative discharge codes have been previously used and validated for outcomes research in a variety of diseases [25] [26]. Due to the large number of patients included in the study, there is a risk of identifying statistically significant findings which are of no clinical significance. We reported ORs and 95\% CIs to de- 
termine the strength of the correlations and improve interpretation. There are no laboratory values or medication data in the NIS (i.e., unable to determine use of immuno-modulators, or post-operative DVT prophylaxis), and no details about disease duration or distribution. This study demonstrated only an association between IBD and worse hospital outcomes in patients with appendicitis undergoing appendectomy. However, determination of causality would require a prospective study.

Despite the above limitations, our study also has several strengths. The NIS database provides a large number of patients with a discharge diagnosis of IBD who underwent appendectomy for appendicitis, which may not be possible from single center or multicenter studies. The benefit of using the NIS database is the results also represent the current national in-patient health-care utilization of IBD patients with appendicitis who underwent appendectomy.

\section{Conclusion}

IBD patients with appendicitis undergoing appendectomy had worse hospital outcomes when compared to non-IBD patients. Efforts should be made to give DVT prophylaxis for all IBD patients undergoing appendectomy as the risk of venous thromboembolism (DVT and PE) is very high. Pre-operative anemia in $\mathrm{CD}$ patients should be treated adequately with intravenous iron infusions as correcting anemia would improve surgical outcomes. Though laparoscopic approach is ideal for appendectomy, it is reasonable to have low threshold to convert to open appendectomy in CD patients, owing to increased association with perforated appendicitis.

\section{References}

[1] Parian, A., Limketkai, B., Koh, J., Brant, S.R., Bitton, A., Cho, J.H., et al. (2016) Appendectomy Does Not Decrease the Risk of Future Colectomy in UC: Results from a Large Cohort and Meta-Analysis. Gut.

[2] Kaser, A., Zeissig, S. and Blumberg, R.S. (2010) Inflammatory Bowel Disease. Annual Review of Immunology, 28, 573-621. https://doi.org/10.1146/annurev-immunol-030409-101225

[3] Cohen, R.D. (2002) The Quality of Life in Patients with Crohn's Disease. Alimentary Pharmacology \& Therapeutics, 16, 1603-1609. https://doi.org/10.1046/j.1365-2036.2002.01323.x

[4] Longobardi, T., Jacobs, P. and Bernstein, C.N. (2003) Work Losses Related to Inflammatory Bowel Disease in the United States: Results from the National Health Interview Survey. The American Journal of Gastroenterology, 98, 1064-1072.

[5] McLeod, R.S., Churchill, D.N., Lock, A.M., Vanderburgh, S. and Cohen, Z. (1991) Quality of Life of Patients with Ulcerative Colitis Preoperatively and Postoperatively. Gastroenterology, 101, 1307-1313. https://doi.org/10.1016/0016-5085(91)90081-U

[6] Kappelman, M.D., Rifas-Shiman, S.L., Porter, C.Q., Ollendorf, D.A., Sandler, R.S., Galanko, J.A., et al. (2008) Direct Health Care Costs of Crohn's Disease and Ulcerative Colitis in US Children and Adults. Gastroenterology, 135, 1907-1913. https://doi.org/10.1053/j.gastro.2008.09.012 
[7] Addiss, D.G., Shaffer, N., Fowler, B.S. and Tauxe, R.V. (1990) The Epidemiology of Appendicitis and Appendectomy in the United States. American Journal of Epidemiology, 132, 910-925. https://doi.org/10.1093/oxfordjournals.aje.a115734

[8] Sauerland, S., Jaschinski, T. and Neugebauer, E.A. (2010) Laparoscopic versus Open Surgery for Suspected Appendicitis. The Cochrane Database of Systematic Reviews, 10, CD001546. https://doi.org/10.1002/14651858.CD001546.pub3

[9] Zhang, C., Krishna, S.G., Hinton, A., Arsenescu, R., Levine, E.J. and Conwell, D.L. (2016) Cytomegalovirus-Related Hospitalization Is Associated With Adverse Outcomes and Increased Health-Care Resource Utilization in Inflammatory Bowel Disease. Clinical and Translational Gastroenterology, 7, e150. https://doi.org/10.1038/ctg.2016.10

[10] Krishna, S.G., Hinton, A., Oza, V., Hart, P.A., Swei, E., El-Dika, S., et al. (2015) Morbid Obesity Is Associated with Adverse Clinical Outcomes in Acute Pancreatitis: A Propensity-Matched Study. The American Journal of Gastroenterology, 110, 1608-1619. https://doi.org/10.1038/ajg.2015.343

[11] Gearhart, S.L., Nathan, H., Pawlik, T.M., Wick, E., Efron, J. and Shore, A.D. (2012) Outcomes from IBD-Associated and Non-IBD-Associated Colorectal Cancer: A Surveillance Epidemiology and End Results Medicare Study. Diseases of the Colon and Rectum, 55, 270-277. https://doi.org/10.1097/DCR.0b013e318242620f

[12] Scott, A., Shekherdimian, S., Rouch, J.D., Sacks, G.D., Dawes, A.J., Lui, W.Y., et al. (2017) Same-Day Discharge in Laparoscopic Acute Non-Perforated Appendectomy. Journal of the American College of Surgeons, 224, 43-48. https://doi.org/10.1016/j.jamcollsurg.2016.10.026

[13] van Langenberg, D.R., Simon, S.B., Holtmann, G.J. and Andrews, J.M. (2010) The Burden of Inpatient Costs in Inflammatory Bowel Disease and Opportunities to Optimize Care: A Single Metropolitan Australian Center Experience. Journal of Crohn's \& Colitis, 4, 413-421. https://doi.org/10.1016/j.crohns.2010.01.004

[14] Van Arendonk, K.J., Tymitz, K.M., Gearhart, S.L., Stem, M. and Lidor, A.O. (2013) Outcomes and Costs of Elective Surgery for Diverticular Disease: A Comparison with Other Diseases Requiring Colectomy. JAMA Surgery, 148, 316-321. https://doi.org/10.1001/jamasurg.2013.1010

[15] Chung, W.S., Lin, C.L., Hsu, W.H. and Kao, C.H. (2015) Inflammatory Bowel Disease Increases the Risks of Deep Vein Thrombosis and Pulmonary Embolism in the Hospitalized Patients: A Nationwide Cohort Study. Thrombosis Research, 135, 492-496. https://doi.org/10.1016/j.thromres.2014.12.025

[16] Yuhara, H., Steinmaus, C., Corley, D., Koike, J., Igarashi, M., Suzuki, T., et al. (2013) Meta-Analysis: the Risk of Venous Thromboembolism in Patients with Inflammatory Bowel Disease. Alimentary Pharmacology \& Therapeutics, 37, 953-962. https://doi.org/10.1111/apt.12294

[17] Miehsler, W., Reinisch, W., Valic, E., Osterode, W., Tillinger, W., Feichtenschlager, T., et al. (2004) Is Inflammatory Bowel Disease an Independent and Disease Specific Risk Factor for Thromboembolism? Gut, 53, 542-548. https://doi.org/10.1136/gut.2003.025411

[18] Ananthakrishnan, A.N., Cagan, A., Gainer, V.S., Cheng, S.C., Cai, T., Scoville, E., et al. (2014) Thromboprophylaxis Is Associated with Reduced Post-Hospitalization Venous Thromboembolic Events in Patients with Inflammatory Bowel Diseases. Clinical Gastroenterology and Hepatology. The Official Clinical Practice Journal of the American Gastroenterological Association, 12, 1905-1910.

https://doi.org/10.1016/j.cgh.2014.02.034 
[19] Nemes, R.M., Pop, C.S., Calagiu, D., Dobrin, D., Chetroiu, D., Jantea, P., et al. (2016) Anemia in Inflammatory Bowel Disease More Than an Extraintestinal Complication. Revista medico-chirurgicala a Societatii de Medici si Naturalisti din Iasi, 120, 34-39.

[20] Atug, O., Kani, H.T., Banzragch, M., Imeryuz, N. and Akin, H. (2016) Incidence Rate of Anemia in Inflammatory Bowel Diseases. The Turkish Journal of Gastroenterology: The Official Journal of Turkish Society of Gastroenterology, 27, 143-148. https://doi.org/10.5152/tjg.2016.16011

[21] Li, Y., Stocchi, L., Rui, Y., Liu, G., Gorgun, E., Remzi, F.H., et al. (2015) Perioperative Blood Transfusion and Postoperative Outcome in Patients with Crohn's Disease Undergoing Primary Ileocolonic Resection in the "Biological Era". Journal of Gastrointestinal Surgery: Official Journal of the Society for Surgery of the Alimentary Tract, 19, 1842-1851. https://doi.org/10.1007/s11605-015-2893-1

[22] Gasche, C., Berstad, A., Befrits, R., Beglinger, C., Dignass, A., Erichsen, K., et al. (2007) Guidelines on the Diagnosis and Management of Iron Deficiency and Anemia in Inflammatory Bowel Diseases. Inflammatory Bowel Diseases, 13, 1545-1553. https://doi.org/10.1002/ibd.20285

[23] Whalen, D., Houchens, R. and Elixhauser, A. (2005) 2002 HCUP Nationwide Inpatient Sample (NIS) Comparison Report. HCUP Method Series Report. U.S. Agency for Healthcare Research and Quality, June 24, Report No. 2005-03.

[24] Nguyen, G.C., Bayless, T.M., Powe, N.R., Laveist, T.A. and Brant, S.R. (2007) Race and Health Insurance Are Predictors of Hospitalized Crohn's Disease Patients Undergoing Bowel Resection. Inflammatory Bowel Diseases, 13, 1408-1416. https://doi.org/10.1002/ibd.20200

[25] Ananthakrishnan, A.N., McGinley, E.L. and Binion, D.G. (2008) Does It Matter Where You Are Hospitalized for Inflammatory Bowel Disease? A Nationwide Analysis of Hospital Volume. The American Journal of Gastroenterology, 103, 2789-2798. https://doi.org/10.1111/j.1572-0241.2008.02054.x

[26] Ananthakrishnan, A.N., McGinley, E.L., Binion, D.G. and Saeian, K. (2011) A Nationwide Analysis of Changes in Severity and Outcomes of Inflammatory Bowel Disease Hospitalizations. Journal of Gastrointestinal Surgery. Official Journal of the Society for Surgery of the Alimentary Tract, 15, 267-276.

https://doi.org/10.1007/s11605-010-1396-3 


\section{Appendix 1}

Table A1. ICD-9 codes.

\begin{tabular}{|c|c|c|}
\hline & Variable/Outcome & ICD-9 codes \\
\hline \multirow{2}{*}{ IBD } & Crohn's Disease (CD) & $555,555.0,555.1,555.2$, and 555.9 \\
\hline & Ulcerative Colitis (UC) & $556,556.0,556.1,556.2,556.3,556.4,556.5,556.6,556.8,556.9$ \\
\hline \multirow[t]{2}{*}{ Appendicitis } & Perforated & $540.0,540.1$ \\
\hline & Non-Perforated & $540.09,541,542$ \\
\hline \multirow[t]{7}{*}{ Appendectomy } & Open & 47.09 \\
\hline & Laparoscopic & 47.01 \\
\hline & Central Nervous System & $997.0,997.00,997.01,997.02,997.09$ \\
\hline & Cardiac & 997.1 \\
\hline & Peripheral Vascular & $997.2,999.2$ \\
\hline & Respiratory & $512.1,997.3,997.31,997.39$ \\
\hline & Gastrointestinal & $997.4,997.49$ \\
\hline \multirow{14}{*}{$\begin{array}{l}\text { Post-operative } \\
\text { complications }\end{array}$} & Genitourinary & 997.5 \\
\hline & Hemorrhage, hematoma, or Seroma & $998.1,998.11,998.12,998.13,998.2,998.51$ \\
\hline & $\begin{array}{l}\text { Wound dehiscence, rupture, nonhealing, } \\
\text { disruption }\end{array}$ & $998.3,998.83,998.0,998.31,998.32,998.33$ \\
\hline & Postoperative Infection & $998.5,998.51,998.59$ \\
\hline & Deep Vein Thrombosis & $453.4,453.40,453.41,453.42$ \\
\hline & Pulmonary Embolism & $415.1,415.11,415.19$ \\
\hline & Postoperative Anemia & 285.1 \\
\hline & Foreign Object Retained After Surgery & $998.4,998.7$ \\
\hline & Air Embolism & 999.1 \\
\hline & Blood Incompatibility & $999.6,999.60,999.61,999.62,999.63,999.69$ \\
\hline & Pressure Ulcer Stages II \& IV & $707.23,707.24$ \\
\hline & Falls and Trauma & $800-829,830-839,850-854,925-929,940-949,991-994$ \\
\hline & Catheter-Associated UTI & 996.64 \\
\hline & Vascular Catheter-Associated Infection & 999.31 \\
\hline \multirow[t]{7}{*}{ HAC } & Manifestations of Poor Glycemic Control & $250.10-250.13,250.20-250.23,251.0,249.10-249.11,249.20-249.21$ \\
\hline & Surgical Site Infection, Mediastinitis, Following & 519.2 \\
\hline & CABG & And one of the following procedure codes: $36.10-36.19$ \\
\hline & $\begin{array}{l}\text { Surgical Site Infection Following Certain } \\
\text { Orthopedic Procedures }\end{array}$ & $\begin{array}{l}996.67,998.59 \\
\text { And one of the following procedure codes: } 81.01-81.08,81.23,81.24 \text {, } \\
81.31-81.38,81.83,81.85\end{array}$ \\
\hline & Surgical Site Infection Following Bariatric & $539.01,539.81,998.59$ \\
\hline & Surgery for Obesity & And one of the following procedure codes: $44.38,44.39,44.95$ \\
\hline & $\begin{array}{l}\text { Deep Vein Thrombosis and Pulmonary } \\
\text { Embolism Following Certain Orthopedic } \\
\text { Procedures }\end{array}$ & $\begin{array}{l}415.11,415.13,415.19,453.40-453.42 \\
\text { And one of the following procedure codes: } 00.85-00.87,81.51-81.52,81.54\end{array}$ \\
\hline
\end{tabular}




\section{Supplementary}

Table S1. Missing data.

\begin{tabular}{cc}
\hline & Percent Missing \\
\hline Gender & $0.94 \%$ \\
Race & $9.37 \%$ \\
Income & $2.33 \%$ \\
Type of insurance & $0.28 \%$ \\
Hospital location/teaching status & $0.61 \%$ \\
Hospital size & $0.61 \%$ \\
Hospital region & $0.00 \%$ \\
\hline
\end{tabular}


Table S2. Univariate analysis of Elixhauser comorbidities of non-inflammatory bowel disease (IBD), Crohn's disease (CD), and ulcerative colitis (UC).

\begin{tabular}{|c|c|c|c|c|c|c|c|c|}
\hline \multirow[b]{2}{*}{ AIDS } & \multicolumn{2}{|c|}{$\begin{array}{c}\text { No IBD } \\
(\mathrm{n}=\mathbf{8 4 5 , 0 5 1 )} \\
\end{array}$} & \multicolumn{2}{|c|}{$\begin{array}{c}C D \\
(n=2416)\end{array}$} & \multirow{2}{*}{$\begin{array}{c}\text { p-value } \\
--\end{array}$} & \multicolumn{2}{|c|}{$\begin{array}{c}\text { UC } \\
(\mathrm{n}=1845)\end{array}$} & \multirow{2}{*}{$\frac{\text { p-value }}{--}$} \\
\hline & 1035 & $0.12 \%$ & 0 & $0.00 \%$ & & 0 & $0.00 \%$ & \\
\hline Alcohol Abuse & 9655 & $1.14 \%$ & 51 & $2.10 \%$ & 0.051 & 41 & $2.22 \%$ & 0.057 \\
\hline Anemia & 28,085 & $3.32 \%$ & 195 & $8.06 \%$ & $<0.001$ & 147 & $7.98 \%$ & $<0.001$ \\
\hline $\begin{array}{c}\text { Rheumatoid } \\
\text { Arthritis/Collagen } \\
\text { Vascular Disease }\end{array}$ & 6884 & $0.81 \%$ & 50 & $2.05 \%$ & 0.003 & 30 & $1.64 \%$ & 0.080 \\
\hline Chronic Blood Loss & 1567 & $0.19 \%$ & $\leq 10$ & $0.17 \%$ & 0.944 & 15 & $0.83 \%$ & 0.005 \\
\hline Congestive Heart Failure & 9821 & $1.16 \%$ & 44 & $1.83 \%$ & 0.169 & 45 & $2.44 \%$ & 0.023 \\
\hline Chronic Lung Disease & 63,243 & $7.48 \%$ & 208 & $8.62 \%$ & 0.354 & 186 & $10.08 \%$ & 0.055 \\
\hline Coagulopathy & 7256 & $0.86 \%$ & 29 & $1.20 \%$ & 0.415 & 30 & $1.62 \%$ & 0.112 \\
\hline Depression & 38,962 & $4.61 \%$ & 185 & $7.64 \%$ & 0.001 & 179 & $9.70 \%$ & $<0.001$ \\
\hline Diabetes Mellitus & 54,488 & $6.45 \%$ & 175 & $7.26 \%$ & 0.459 & 166 & $9.02 \%$ & 0.052 \\
\hline $\begin{array}{c}\text { Diabetes with Chronic } \\
\text { Complications }\end{array}$ & 5907 & $0.70 \%$ & $\leq 10$ & $0.21 \%$ & 0.195 & $\leq 10$ & $0.54 \%$ & 0.718 \\
\hline Drug Abuse & 10,973 & $1.30 \%$ & 30 & $1.23 \%$ & 0.890 & 20 & $1.11 \%$ & 0.747 \\
\hline Hypertension & 180,280 & $21.33 \%$ & 528 & $21.87 \%$ & 0.769 & 537 & $29.10 \%$ & $<0.001$ \\
\hline Hypothyroidism & 38,128 & $4.51 \%$ & 145 & $6.02 \%$ & 0.115 & 128 & $6.94 \%$ & 0.031 \\
\hline Liver Disease & 8805 & $1.04 \%$ & 29 & $1.18 \%$ & 0.755 & 69 & $3.73 \%$ & $<0.001$ \\
\hline Lymphoma & 1279 & $0.15 \%$ & $\leq 10$ & $0.21 \%$ & 0.753 & 0 & $0.00 \%$ & -- \\
\hline $\begin{array}{c}\text { Fluid and Electrolyte } \\
\text { Disorders }\end{array}$ & 69,211 & $8.19 \%$ & 374 & $15.47 \%$ & $<0.001$ & 293 & $15.90 \%$ & $<0.001$ \\
\hline Metastatic Cancer & 1284 & $0.15 \%$ & $\leq 10$ & $0.21 \%$ & 0.757 & 0 & $0.00 \%$ & -- \\
\hline Neurological Disease & 14,172 & $1.68 \%$ & 78 & $3.24 \%$ & 0.007 & 30 & $1.64 \%$ & 0.955 \\
\hline Obesity & 70,452 & $8.34 \%$ & 154 & $6.38 \%$ & 0.113 & 149 & $8.10 \%$ & 0.874 \\
\hline Paralysis & 2418 & $0.29 \%$ & 11 & $0.44 \%$ & 0.532 & 0 & $0.00 \%$ & -- \\
\hline Peripheral Vascular Disease & 8121 & $0.96 \%$ & 20 & $0.82 \%$ & 0.750 & 36 & $1.93 \%$ & 0.058 \\
\hline Psychoses & 12,536 & $1.48 \%$ & 89 & $3.70 \%$ & $<0.001$ & 60 & $3.28 \%$ & 0.005 \\
\hline $\begin{array}{c}\text { Pulmonary Circulation } \\
\text { Disorders }\end{array}$ & 2531 & $0.30 \%$ & 15 & $0.62 \%$ & 0.206 & $\leq 10$ & $0.46 \%$ & 0.534 \\
\hline Renal Failure & 13,371 & $1.58 \%$ & 19 & $0.78 \%$ & 0.144 & 41 & $2.20 \%$ & 0.340 \\
\hline $\begin{array}{c}\text { Solid Tumor without } \\
\text { Metastasis }\end{array}$ & 3755 & $0.44 \%$ & $\leq 10$ & $0.22 \%$ & 0.472 & 18 & $0.98 \%$ & 0.103 \\
\hline Peptic Ulcer Disease & 68 & $0.01 \%$ & 0 & $0.00 \%$ & -- & 0 & $0.00 \%$ & -- \\
\hline Valvular Disease & 9206 & $1.09 \%$ & 31 & $1.27 \%$ & 0.708 & 52 & $2.84 \%$ & 0.001 \\
\hline Weight Loss & 5748 & $0.68 \%$ & 83 & $3.42 \%$ & $<0.001$ & 45 & $2.46 \%$ & $<0.001$ \\
\hline
\end{tabular}

